\title{
Problems in the Revision of Failed Moore Prosthesis
}

\author{
A. Lachkar, A. Najib and H. Yacoubi
}

\begin{abstract}
Over the years, Moore prosthesis has been described as a good option in the treatment of femoral neck fracture. Its main disadvantages are about femoral fixation and the acetabular erosion. Because of less cost, it still be used improperly and provide a large number of failures. Improper placement of the Moore prosthesis provide biomechanical disturbances of the arthroplasty. The insufficient of residual femoral neck length or the insufficient of metaphyseal fill are associated with the failure of the Moore arthroplasty. The aim of our study is to report and evaluate intraoperative findings and difficulties while we were convert failed aseptic Moore hemiarthroplasty into cemented total hip arthroplasty.
\end{abstract}

Index Terms - Hip arthroplasty, Moore prosthesis, Replacement surgery.

\section{INTRODUCTION}

Over the years, Moore prosthesis has been described as a good option in the treatment of femoral neck fracture. Its main disadvantages are about femoral fixation and the acetabular erosion. Because of less cost, it still be used improperly and provide a large number of failures. Improper placement of the Moore prosthesis provide biomechanical disturbances of the arthroplasty. The insufficient of residual femoral neck length or the insufficient of metaphyseal fill are associated with the failure of the Moore arthroplasty [1], [2].

The aim of our study is to report and evaluate intraoperative findings and difficulties while we were convert failed aseptic Moore hemiarthroplasty into cemented total hip arthroplasty.

\section{MATERIALS AND METHODS}

Thirteen total hip arthroplasties conversion for failed aseptic Moore prosthesis were performed at the orthopedic surgery department between 2015 and 2020. There were 7 men and 6 women. The mean age was 71 years $(65-76$ years). The mean time to failure was 42 months (18-76 months). The mean preoperative Parker Score was 6. Creactive protein (CRP) was measured before the surgery to exclude infection.

\section{RESULTS}

All the patients were operated using the posterolateral approach. The main perioperative difficulties that we found

Published on July 17, 2020.

A. Lachkar, CHU Oujda, Morocco.

(corresponding e-mail: dr.lachkar@gmail.com)

A. Najib, CHU Oujda, Morocco.

H. Yacoubi, CHU Oujda, Morocco. were encountered during the exposure, the dislocation of Moore prosthesis, and specially its extraction. Indeed, the capsule and the external rotators were too difficult to identify because of the fibrosis, this scar tissue was too complex to elevate and a special attention was required to prevent sciatic nerve injury. A meticulous scar tissue release was performed from all around the Moore prosthesis. The dislocation was difficult and we checked every time the synchronous motion prosthesis with femur to avoid iatrogenic fractures. The proximal periprosthetic and piriform muscle fossa were cleared very carefully so as to visualize clearly prosthesis extraction holes. The prosthesis was extracted using a universal extractor. Femoral reaming was done using cannulated reamers. Acetabular and femoral preparation were done using standard techniques. The global functional results were good using Harris Hip Score (Mean follow-up duration was 3 years) (Fig. 1-2).

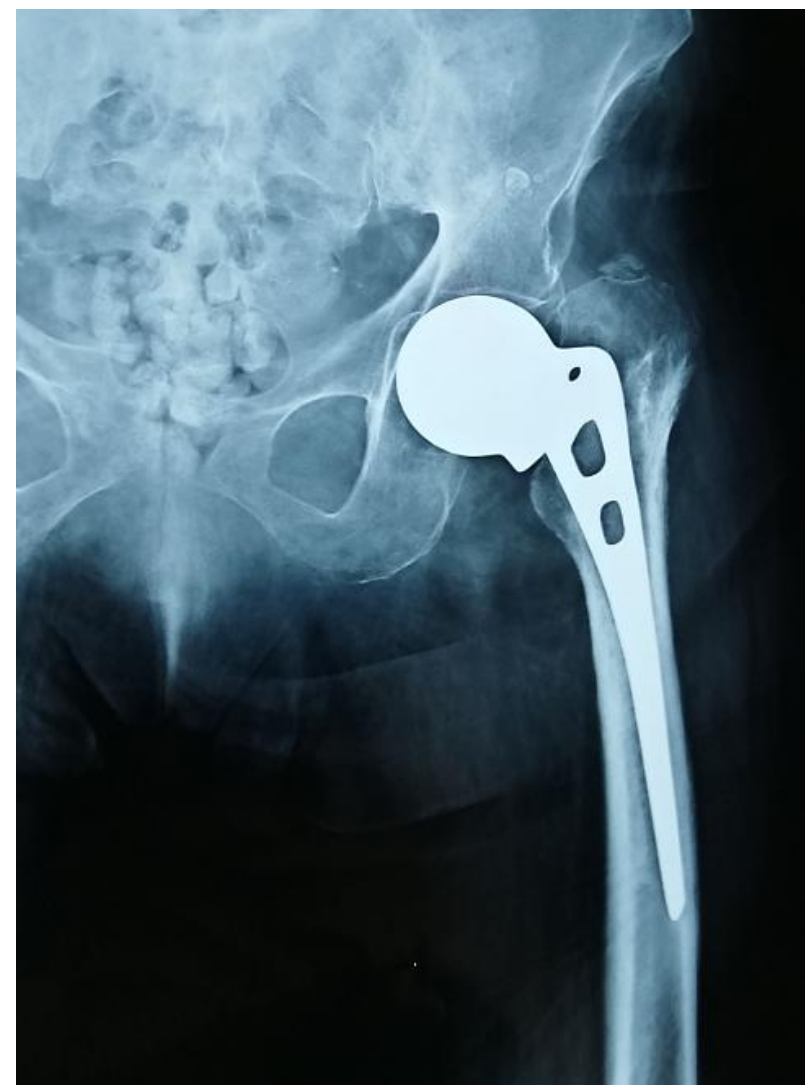

Fig. 1. X-rays of failed aseptic Moore prosthesis.

\section{DISCUSSION}

Femoral neck fractures in elderly patients have been treated with Moore prosthesis. It has provide too many complications and had been associated with a bad quality of life [1], [2]. 


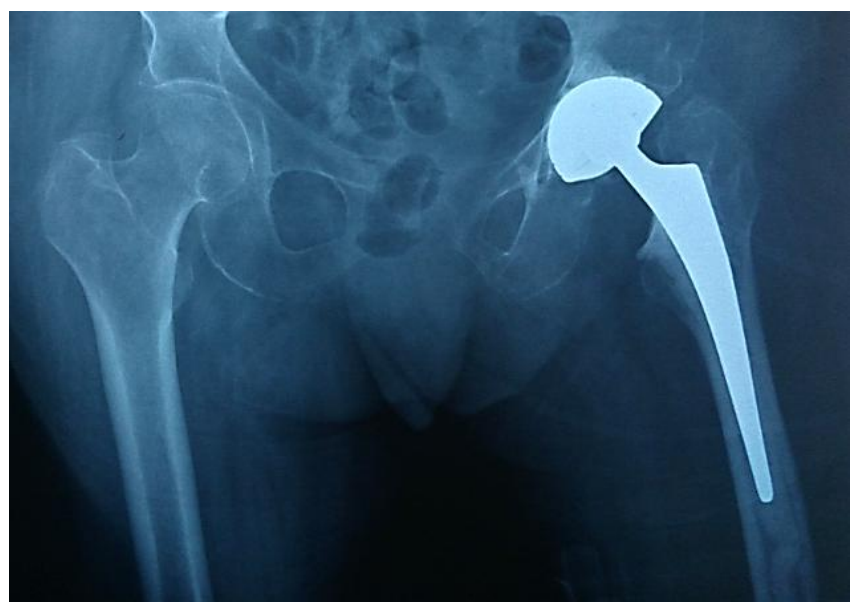

Fig. 2. Replacement of Moore prosthesis by a total hip arthroplasty.

Before performing the conversion to a total hip arthroplasty, the preoperative planning is an important and crucial time before surgery. We need to evaluate the acetabular bone quality, femoral bone quality, and status of the greater trochanter. Also, we need to explore the clinical range of motion, and power of the abductors muscles. The removal of fibrotic tissue is a difficult surgical time. We need to perform it from the intertrochanteric ridge. A special attention must be payed to the sciatic nerve. We need also to release all the fibrosis and scar tissue prior to dislocation. The dislocation of the prosthesis must be meticulous to avoid femoral or acetabular fractures. Then, we need to clear all the piriform fossa from fibrous tissue and have a good visualization of the extraction holes [3]-[7].

Sometimes, some bone plugs are formed around the extraction holes. In those cases we need to use thin osteotomes to clear the bone plugs. Finally, to extract the Moore prosthesis, universal extractors are useful and we need to apply a gentle force in the direction of medullary canal. Cannulated reamers must be used to prepare the femur. We need to perform it gently and widely to remove all the fibrous membrane. Debris of such membrane produce prostaglandin E2, interleukin $1 \mathrm{~b}$ and collagenase and may contribute to failure of the total hip arthroplasty by resorption of adjacent bone. If the implant is broken, we can extract it by a trans-femoral approach. We recommend the use of a distal fenestration to remove it [8]-[11].

The results after the totalization of the hip arthroplasty have been reported in several papers. Too many authors reported good functional results after such surgery, even when the extraction of the implant were too difficult perioperatively. Function improved with time after the total hip arthroplasty [10]-[12].

\section{CONCLUSION}

The conversion hip arthroplasty is a great option to treat failed Moore prosthesis. It restores the function and suppress the pain. However, the exposition and the extraction of the old implant may be challenging and must be wisely planned before performing such surgery.

\section{REFERENCES}

[1] P. Bhosale, A. Suryawanshi, A. Mittal. Total hip arthroplasty for failed aseptic Austin Moore prosthesis. Indian J Orthop. 2012;46(3):297-303.

[2] V. J. Purushotham, B. T. Ranganath. Total Hip Arthroplasty in a Girdlestone Hip following a Failed Hemiarthroplasty. J Orthop Case Rep. 2015;5(2):47-49.

[3] W. P. Yau, K. Y. Chiu. Critical radiological analysis after Austin Moore hemiarthroplasty. Injury. 2004;35:1020-4.

[4] S. W. Wachtl, R. P. Jacob, E. Gautier. Ten-year patient and prosthesis survival after unipolar hip hemiarthroplasty in female patients over 70 years old. J Arthoplasty. 2003;18:587-91.

[5] M. Clayer, J. Brucknr. The outcome of Austin-Moore hemiarthroplasty for fracture of the femoral neck. Am J Orthop. 1997;26:681-4.

[6] E. S. Bittar, W. Petty. (1982) Girdlestone arthroplasty for infected total hip arthroplasty. Clin Orthop. 170:83-87.

[7] R. T. Muller, K. F. Schlegel, H. Konermann. (1989) Long-term results of Girdlestone hip. Arch Orthop Trauma Surg. 108:359-362

[8] E. Lenoble, D. Goutallier. (1995) Replacement of infected total hip prosthesis in two stages. Int Orthop. 19:151-156.

[9] PM. Witschger, H. Siegrist. Totalprothese nach Girdlestone. Orthopäde. 1989;18:489-492.

[10] R. Oheim. Surgical therapy of hip-joint empyema. Is the Girdlestone arthroplasty still up to date? International Orthopaedics [Int Orthop] 2012 May;36(5):927-33.

[11] K. M. Sharif, M. J. Parker. Austin Moore hemiarthroplasty: technical aspects and their effects on outcome, in patients with fractures of the neck of femur. Injury. 2002;33(5):419-422.

[12] A. Guimont, A. Girard. A propos de la prothèse de Moore [Moore prosthesis]. Union Med Can. 1976;105(1):43-50.

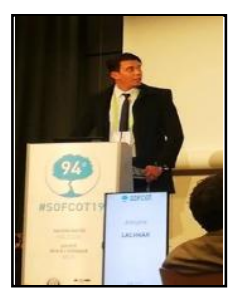

A. Lachkar is the principal author of this paper. He is an MD specialized in orthopedic surgery. He exercises as a surgeon in the Mohammed-VI Hospital of Oujda in Morocco. 